\section{OPEN ACCESS}

Edited by:

Haldre S. Rogers,

lowa State University, United States

Reviewed by:

Kim McConkey,

National Institute of Advanced

Studies, India

Onja Harinala Razafindratsima,

University of California, Berkeley,

United States

*Correspondence:

John R. Poulsen

john.poulsen@duke.edu

Specialty section:

This article was submitted to

Population, Community,

and Ecosystem Dynamics,

a section of the journal

Frontiers in Ecology and Evolution

Received: 04 October 2021 Accepted: 06 December 2021 Published: 22 December 2021

Citation:

Poulsen JR, Beirne C, Rundel C, Baldino M, Kim S, Knorr J, Minich T, Jin L, Núñez CL, Xiao S, Mbamy W, Obiang GN, Masseloux J, Nkoghe T,

Ebanega MO, Clark CJ, Fay MJ,

Morkel P, Okouyi J, White LJT and Wright JP (2021) Long Distance Seed

Dispersal by Forest Elephants.

Front. Ecol. Evol. 9:789264.

doi: 10.3389/fevo.2021.789264

\title{
Long Distance Seed Dispersal by Forest Elephants
}

\begin{abstract}
John R. Poulsen ${ }^{1 *}$, Christopher Beirne ${ }^{1,2}$, Colin Rundel ${ }^{3}$, Melissa Baldino', Seokmin Kim ${ }^{1}$, Julia Knorr'1, Taylor Minich', Lingrong Jin', Chase L. Núñez ${ }^{1,5,6}$, Shuyun Xiao ${ }^{7}$, Walter Mbamy ${ }^{8}$, Guichard Ndzeng Obiang ${ }^{8}$, Juliana Masseloux ${ }^{1}$, Tanguy Nkoghe ${ }^{8}$, Médard Obiang Ebanega ${ }^{8}$, Connie J. Clark ${ }^{1}$, Michael J. Fay ${ }^{9}$, Pete Morkel ${ }^{10}$, Joseph Okouyi ${ }^{8}$, Lee J. T. White ${ }^{4,10,11}$ and Justin P. Wright ${ }^{4}$
\end{abstract}

\begin{abstract}
${ }^{1}$ Nicholas School of the Environment, Duke University, Durham, NC, United States, ${ }^{2}$ Department of Forest Resources Management, Faculty of Forestry, University of British Columbia, Vancouver, BC, Canada, ${ }^{3}$ Department of Statistical Science, Trinity College of Arts and Sciences, Duke University, Durham, CA, United States, ${ }^{4}$ African Forest Ecology Group, School of Natural Sciences, University of Stirling, Stirling, United Kingdom, ${ }^{5}$ Department for the Ecology of Animal Societies, Max Planck Institute of Animal Behavior, Konstanz, Germany, ${ }^{6}$ Centre for the Advanced Study of Collective Behaviour, University of Konstanz, Konstanz, Germany, ${ }^{7}$ Department of Biology, Trinity College of Arts and Sciences, Duke University, Durham, NC, United States, ${ }^{8}$ Omar Bongo University, Libreville, Gabon, ${ }^{9}$ Agence Nationale des Parcs Nationaux, Libreville, Gabon, ${ }^{10}$ Independent Researcher, Karasburg, Namibia, ${ }^{11}$ Institut de Recherche en Écologie Tropicale, Libreville, Gabon
\end{abstract}

By dispersing seeds long distances, large, fruit-eating animals influence plant population spread and community dynamics. After fruit consumption, animal gut passage time and movement determine seed dispersal patterns and distances. These, in turn, are influenced by extrinsic, environmental variables and intrinsic, individual-level variables. We simulated seed dispersal by forest elephants (Loxodonta cyclotis) by integrating gut passage data from wild elephants with movement data from 96 individuals. On average, elephants dispersed seeds $5.3 \mathrm{~km}$, with $89 \%$ of seeds dispersed farther than $1 \mathrm{~km}$. The longest simulated seed dispersal distance was $101 \mathrm{~km}$, with an average maximum dispersal distance of $40.1 \mathrm{~km}$. Seed dispersal distances varied among national parks, perhaps due to unmeasured environmental differences such as habitat heterogeneity and configuration, but not with human disturbance or habitat openness. On average, male elephants dispersed seeds farther than females. Elephant behavioral traits strongly influenced dispersal distances, with bold, exploratory elephants dispersing seeds $1.1 \mathrm{~km}$ farther than shy, idler elephants. Protection of forest elephants, particularly males and highly mobile, exploratory individuals, is critical to maintaining long distance seed dispersal services that shape plant communities and tropical forest habitat.

Keywords: seed dispersal, elephant, tropical forest, animal movement, central Africa, gut passage time, long distance dispersal

\section{INTRODUCTION}

Fruit-eating vertebrates play an important role in plant reproduction through seed dispersal (Levin et al., 2003). At local scales, seed dispersal increases plant fitness by potentially reducing competition between parent plants and their progeny and lowering the risk of density-dependent disease and predation (Janzen, 1970). Not only does seed dispersal promote community diversity (Harrison et al., 2013), it also reduces species aggregation (Wandrag et al., 2017). At landscape 
scales, long-distance dispersal (LDD) links local populations within a metapopulation, facilitates gene flow, and promotes migration and colonization of new habitats (Cain et al., 2000; Nathan, 2006). LDD by large vertebrates is of particular interest for biodiversity conservation because large-bodied vertebrates, past and present, are most at risk of human-related extinctions (Davidson et al., 2009). Under global climate change, the loss of large vertebrate seed dispersal services could compromise the survival of plant species that depend on range shifts driven by migration and colonization.

Vertebrate species affect plant community composition and population expansion by shaping the seed shadow - the spatial distribution of seeds relative to the parent plant. After fruit consumption, two key processes determine the seed shadow: gut passage time (GPT), the time between seed ingestion and defecation, and animal movement. Large, wide-ranging species with slow GPTs, therefore, disperse seeds farther on average than small-bodied species with fast GPTs (Vidal et al., 2013; Bunney et al., 2017). GPS technology can precisely measure animal movement (Kays et al., 2015), but measurements of GPT are less precisely known. GPT estimates have primarily depended on trials with captive animals owing to difficulties of relocating ingested seeds in the wild (Kinahan et al., 2007; Campos-Arceiz and Blake, 2011; Harich et al., 2016; Bunney et al., 2017). Captive animals, however, often have different diets and behaviors than wild animals, potentially introducing considerable error into the modeling of realistic seed shadows (Campos-Arceiz et al., 2008).

Most studies of vertebrate seed dispersal have focused on estimating species-level seed dispersal services (Holbrook et al., 2002; Russo et al., 2006; Blake et al., 2009), ignoring individual physiological traits (sex and size) and behavioral differences (boldness, aggressiveness, and sociability) (Zwolak and Sih, 2020). But individuals can vary consistently in behavior, with behaviors often covarying in behavioral syndromes, such as being more or less active (Sih et al., 2004). Behavioral syndromes could have direct ecological effects for seed dispersal (Sih et al., 2012). More exploratory, active foragers, for example, will likely have larger home ranges, higher encounter rates with high quality fruits, and consume more fruit because of higher energy needs (Zwolak and Sih, 2020). Thus, behavioral syndromes that control movement patterns of frugivores might affect seed dispersal distances and even the probability that seeds are deposited in suitable sites for recruitment.

To advance knowledge of seed dispersal for both theory and management, we need to understand the extrinsic, environmental and intrinsic, individual drivers of seed dispersal. Forest elephants (Loxodonta cyclotis) are an ideal model for studying variation in seed dispersal because they are intelligent, highly mobile, keystone seed dispersers in African tropical forests. Forest elephants consume seeds of more species than any other large vertebrate (Beirne et al., 2020) and are the sole disperser of many large or robustly encapsulated seed species (Guimarães et al., 2008; Beaune et al., 2013). With daily travel distances of $7.4 \mathrm{~km}$ per day (Mills et al., 2018) and annual home ranges of $195 \mathrm{~km}^{2}$ (Beirne et al., 2021), they contribute to LDD. Using coarse GPT categories for small and large seeds, Blake et al. (2009) estimated that $88 \%$ of elephant-dispersed seeds were moved $>1 \mathrm{~km}$ and $14 \%$ of seeds were moved $>10 \mathrm{~km}$ from parent plants. Forest elephants, however, likely vary in the quality of their seed dispersal services with habitat use, sex and individual behavior. Male elephants, for example, move farther and have larger home range size and weaker site fidelity than females (Beirne et al., 2021). And, forest elephants exhibit distinct behavioral syndromes along an axis that varies from individuals with smaller home ranges, shorter movement distances and less exploratory behavior to those with larger ranges, longer movement distances and more exploratory behavior (Beirne et al., 2021). Finally, poaching and habitat loss have drastically reduced forest elephant populations in the last two decades (Maisels et al., 2013; Poulsen et al., 2017, 2018), thus we need to understand how the reduction or loss of seed dispersal services provided by elephants could affect forest species composition.

Here we quantify seed dispersal by forest elephants to improve understanding of their role in LDD. To do so, we use a novel experimental approach to: (1) estimate the GPT distribution of wild forest elephants and compare them to existing estimates; (2) model elephant-mediated seed dispersal patterns, using GPS tracking data from 96 elephants; and (3) evaluate the effects of human disturbance, habitat openness, elephant sex, and behavioral syndrome on seed dispersal distances. Filling gaps in the knowledge of a keystone seed disperser contributes to forecasting future forest composition in light of climate change, deforestation, and defaunation.

\section{MATERIALS AND METHODS}

\section{Study Area and Subjects}

Located on the Atlantic coast of central Africa, the Gabonese Republic (Gabon) holds 23 million ha of evergreen forest with $88 \%$ forest cover (Sannier et al., 2014) and high aboveground biomass stores in large trees (Poulsen et al., 2020; Figure 1). In part due to its low human population ( $\sim 1.5$ million people), historic economic dependence on offshore oil, and conservation efforts (creation of 13 national parks in 2004), the country is renowned for its diversity of natural, intact ecosystems and the animal and plant species that inhabit them. The annual mean temperature of Gabon is about $25.0^{\circ} \mathrm{C}$ (1901-2015). On average, temperatures are highest in March $\left(26.2^{\circ} \mathrm{C}\right)$ and lowest in July $\left(23.1^{\circ} \mathrm{C}\right)$. Annual average precipitation is about $1800 \mathrm{~mm}$, but it varies along a west-to-east gradient, declining from $2650 \mathrm{~mm}$ along the Atlantic coast to $1400 \mathrm{~mm}$ in the southeast of the country.

In 2015, the Gabon Parks Agency (ANPN) developed a GPS tracking program to guide elephant management and protection (Mills et al., 2018). Ninety-six elephants were collared between October 2017 and October 2019 in and around five protected areas (Ivindo, Loango, Moukoulaba-Doudou, Mwagna, and Minkébé National Parks and the Wonga Wongué Presidential Reserve) (Figure 1), which vary to some extent in habitat type and weather (Table 1). The field team attempted to collar a balanced sample of males and females; however, males were scarce in some locations. The proportion of collared males at each site was 33\% (Ivindo), 47\% (Loango), 8\% (Minkébé), 20\% Moukoulaba Doudou, 20\% Mwagna, and 55\% Wonga Wongué. For a full description of capture and collaring protocols see 


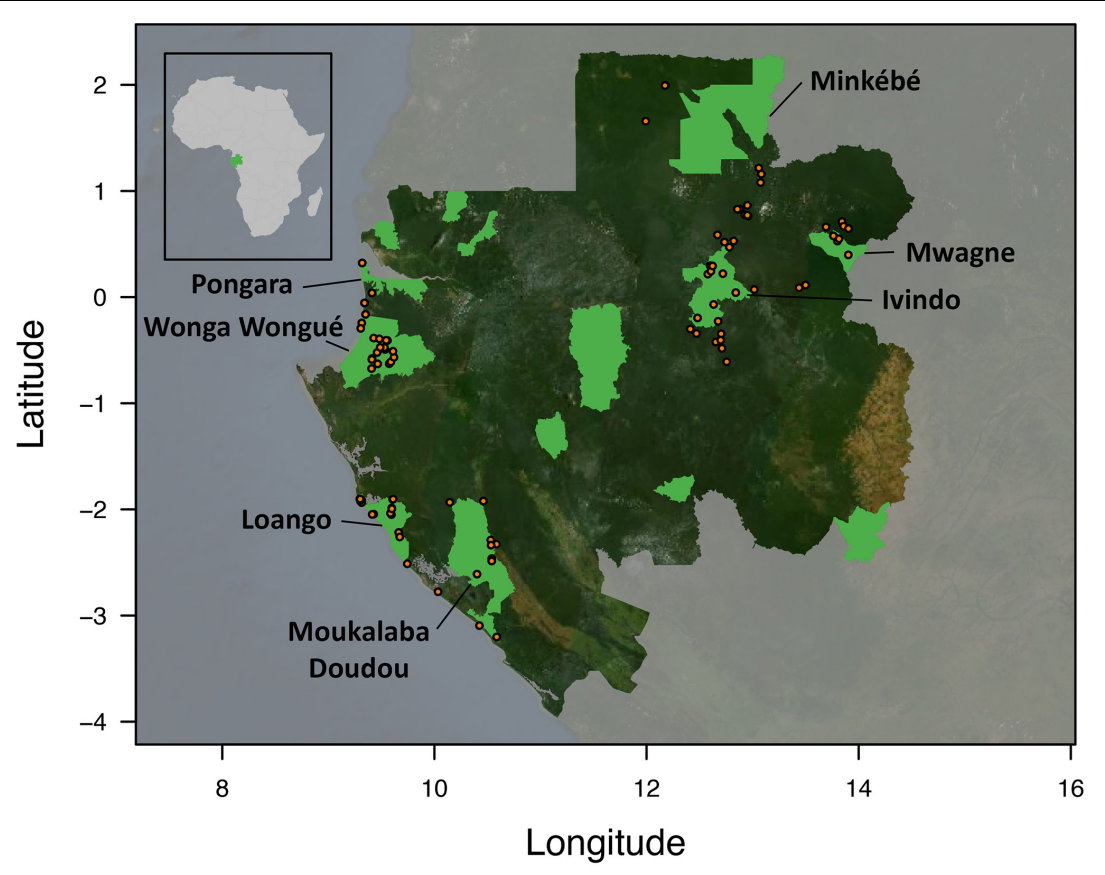

FIGURE 1 | The location of Gabon in Africa (inset) and the approximate locations of the 96 collared elephants (orange points) in and around 7 protected areas (light green polygons) in the country.

Mills et al. (2018). For a short time after deployment of the collars and after 2 years of functioning, a 4- or 12-h GPS fix interval was used, otherwise the collars were set to a 1-h interval. To preclude the possibility that fix interval influences the results, we only use data with fix intervals of $1 \mathrm{~h}$.

\section{Gut Passage Times}

To estimate GPTs of wild forest elephants, we conducted baiting trials and elephant follows between June and August 2018 in and around Ivindo National Park in northeastern Gabon [Figure 1; see Beirne et al. (2019) for details]. The trials consisted of baiting GPS-collared elephants with fruits embedded with experimental seeds, and then following the elephant using its GPS track to recover the seeds. The smallest experimental seeds (pellets) were colored plastic pellets (6 mm diameter Airsport Ammo, $0.11 \mathrm{~g}$ ). Different colors of pellets were employed for each baiting trial to distinguish the origin of pellets recovered in dung. The second type of experimental seed (tin seeds) consisted of hollowed out Chrysophyllum lacourtianum seeds filled with aluminum foil and sealed with medical safe epoxy (Henkel Loctite Hysol M-31CL Medical Device Epoxy). Note that we also tested epoxy-sealed, iButtons as experimental seeds on captive elephants at the North Carolina Zoo and in the field (Beirne et al., 2019). At the zoo, the average GPT for three Savanna elephants (Loxondonta africana) was relatively slow (Figure 2, point 1); in the field, wild forest elephants spat out the iButtons, so they are not included in estimates of seed dispersal distances below (Beirne et al., 2019).

Based on GPS data, we located baiting stations at places likely to be visited by collared elephants. Baiting stations consisted of piles of wild C. lacourtianum fruits, a seasonally and locally abundant elephant-dispersed fruit, and market bought mangos (Mangifera spp.) and ripe plantains (Musa spp.). Each C. lacourtianum fruit was hollowed out, embedded with up to six tin seeds and stuffed with a mixture of C. lacoutianum and plantain fruit flesh and colored pellets. We washed prepared fruits with stream water to reduce the possibility that elephants rejected the seeds due to human handling. In total, each pile contained $250 \mathrm{~g}$ of pellets ( $\sim 2270$ beads) and between 19 and 46 tin seeds. Additional fruit, such as mangos, undisturbed C. lacourtianum and plantains, were added to each pile to make them more attractive to elephants.

Although we attempted to bait multiple elephants, our GPT estimates are derived from a GPS-collared adult female (age 30-40) accompanied by two juveniles (ages 2-3 and 7-8) that traveled as a unit. After a feeding event, we followed the focal elephant for 10 days to record the location of all dung containing experimental seeds. In sum, we followed this group for three separate 10-day periods (see below). The difference in time from the initial feeding event to the timestamp of the GPS point from the elephant movement track closest to the dung was considered the GPT. Using this approach, we obtained 118 GPT observations over three separate elephant follows (Beirne et al., 2019).

\section{Modeling Seed Dispersal}

To estimate a GPT distribution, we fit a Bayesian generalized linear model using a gamma distribution with a log link to estimate relevant parameters (mean, shape, $k$, and scale, $\Theta$; Figure 2). Additional models were fit that included the elephant follow and dung age class as potential explanatory predictors of both mean and shape; however, none of the 
TABLE 1 | Description of primary sites where forest elephants were GPS collared, including the general precipitation patterns and habitat types at each site.

\begin{tabular}{|c|c|c|}
\hline Site and area & Precipitation & Habitat \\
\hline $\begin{array}{l}\text { Ivindo National } \\
\text { Park } \\
2990 \mathrm{~km}^{2}\end{array}$ & $\begin{array}{l}\text { Annual mean: } 1700 \text { mm } \\
\text { Bimodal rainfall with two } \\
\text { relatively dry (January-March } \\
\text { and June-August) and two } \\
\text { rainy seasons } \\
\text { (September-December and } \\
\text { April-May). }\end{array}$ & $\begin{array}{l}\text { Primary and secondary lowland } \\
\text { forest, swamps, and a series of } \\
\text { baïs [forest clearings } \\
\text { maintained by animal activity } \\
\text { Beirne et al. (2020)]. }\end{array}$ \\
\hline $\begin{array}{l}\text { Loango } \\
\text { National Park } \\
1550 \mathrm{~km}^{2}\end{array}$ & $\begin{array}{l}\text { Annual mean: } 2099 \text { mm } \\
\text { Bimodal rainfall with long rainy } \\
\text { season (October-April), } \\
\text { interrupted by a short dry } \\
\text { season (December-January), } \\
\text { and a long dry season } \\
\text { (May-September } \\
\text { Martínez-Íñigo et al., 2021). }\end{array}$ & $\begin{array}{l}\text { Mosaic of rivers, swamps, } \\
\text { coastal forests, mangroves, } \\
\text { savannahs, and secondary and } \\
\text { mature forests, bordered by the } \\
\text { Atlantic Ocean and a lagoon. }\end{array}$ \\
\hline $\begin{array}{l}\text { Moukoulaba- } \\
\text { Doudou } \\
\text { National Park } \\
4500 \mathrm{~km}^{2} \text {. }\end{array}$ & $\begin{array}{l}\text { Annual mean: 1176-2043 mm } \\
\text { One dry season } \\
\text { (May-September) and one rainy } \\
\text { season (October-May Terada } \\
\text { et al., 2021). }\end{array}$ & $\begin{array}{l}\text { Mosaic of forest, savanna, and } \\
\text { papyrus swamp; the park is } \\
\text { divided, north to south, by the } \\
\text { Doudou Mountain Range with } \\
\text { elevations up to } 900 \mathrm{~m} \text {. }\end{array}$ \\
\hline $\begin{array}{l}\text { Mwagna } \\
\text { National Park } \\
1160 \mathrm{~km}^{2}\end{array}$ & $\begin{array}{l}\text { Annual mean: } 1700 \text { mm } \\
\text { Bimodal rainfall with two } \\
\text { relatively dry (January-March } \\
\text { and June-August) and two } \\
\text { rainy seasons } \\
\text { (September-December and } \\
\text { April-May). }\end{array}$ & $\begin{array}{l}\text { Primary and secondary lowland } \\
\text { forest, swamps, and a series of } \\
\text { baïs. }\end{array}$ \\
\hline $\begin{array}{l}\text { Minkébé } \\
\text { National Park } \\
7570 \text { km² }^{2}\end{array}$ & $\begin{array}{l}\text { Annual mean: 1500-1800 mm } \\
\text { Bimodal rainfall with two } \\
\text { relatively dry (January-March } \\
\text { and June-August) and two } \\
\text { rainy seasons } \\
\text { (September-December and } \\
\text { April-May). }\end{array}$ & $\begin{array}{l}\text { Diversity of habitats including } \\
\text { primary lowland forest, } \\
\text { inselberg forest, herbaceous } \\
\text { swamps, and seasonally } \\
\text { flooded river valleys. } \\
\text { Landscape includes hills and } \\
\text { inselbergs, so that elevations } \\
\text { range from } 450-900 \text { m } \\
\text { Huijbregts et al., } 2003 \text {. }\end{array}$ \\
\hline $\begin{array}{l}\text { Wonga } \\
\text { Wongué } \\
\text { Presidential } \\
\text { Reserve } \\
4250 \mathrm{~km}^{2} \text {. }\end{array}$ & $\begin{array}{l}\text { Annual mean } 2600 \text { mm } \\
\text { Bimodal rainfall with two dry } \\
\text { seasons (May-October and } \\
\text { December-January) and two } \\
\text { wet seasons (January-May and } \\
\text { October-December Mills et al., } \\
\text { 2018). }\end{array}$ & $\begin{array}{l}\text { Variety of habitats, from white } \\
\text { sand beaches and mangrove } \\
\text { wetlands on the Atlantic coast } \\
\text { to a mosaic of open grasslands } \\
\text { and tropical forest in the interior } \\
\text { made up of } 85 \% \text { lowland forest } \\
\text { and } 15 \% \text { savanna. }\end{array}$ \\
\hline
\end{tabular}

parameters from these models differed significantly from the combined model.

Simulations of possible seed shadows were constructed using a Monte Carlo simulation of seed dispersal by sampling time from the GPT distribution and then using these values to conditionally sample from an empirically determined distribution of elephant movement. This empirical distribution was constructed from timestamped GPS movement tracking data of forest elephants in Gabon. These data consist of hourly latitude and longitude coordinates for 96 different elephants collected between 2015 and 2019 (Beirne et al., 2021). Specifically, these hourly observations for each elephant observations were differenced with all subsequent observations to calculate $\Delta \mathrm{t}$, change in time, $\Delta \mathrm{d}$, change in distance, $\Delta \mathrm{x}$, change in east/west distance, and $\Delta \mathrm{y}$, change in north/south distance. Only pairs with a $\Delta \mathrm{t}$ of less than
7 days were used as all observed GPTs were below $100 \mathrm{~h}$. Kernel density estimates were then constructed of $\Delta \mathrm{t}, \Delta \mathrm{d}, \Delta \mathrm{x}$, and $\Delta \mathrm{y}$ separately for each elephant and for all differenced elephant data combined. These were then used to simulate the 1 dimensional seed distance distribution (Figure 3 ) and the 2 dimensional seed shadow distributions (Figures 4, 5).

\section{Drivers of Variation in Seed Dispersal Distance}

To evaluate drivers of variation in seed dispersal distances, we modeled median seed dispersal distance, $\Delta \mathrm{d}$, for each elephant as a linear model incorporating extrinsic (site, human footprint index, and habitat) and intrinsic (sex, behavioral syndrome) factors as independent variables. Site was defined as the protected area in which the collared elephant occurred, or the closest protected area to its home range. We assessed the role of human disturbance on seed dispersal distances by including the mean annual human footprint index (HFI) for the home range of each elephant (Wildlife Conservation Society WCS, and Center for International Earth Science Information Network - CIESIN - Columbia University, 2005). The HFI spatial raster is derived from nine data layers reflecting three key elements: human population (population density); human land use and infrastructure (built-up areas, nighttime lights, land use/land cover); and human access (coastlines, roads, railroads, and navigable rivers). Habitat was included by quantifying the proportional use of forest habitat by each elephant. Using discrete classifications of habitat types from the CGLS-LC100 Collection $3^{1}$, we collapsed five habitat types into either "open" (grassland, savanna, and bare ground) or "closed" (forest) categories for each GPS fix, and then calculated the proportion of all GPS fixes in forest for each elephant. Sex was recorded during the collaring of each elephant. Behavioral syndrome was incorporated as the degree of exploratory behavior from Beirne et al. (2021), where negative values represent idlers (small home ranges, short movement distances, and low exploratory behavior) and positive values represent explorers (large home range, long movement distances, and low exploratory behavior).

We built a full linear model, including main effects for HFI, forest, and exploratory behavior, and an interaction between sex and site to account for the uneven ratios of males and females at each site. We then used backward model selection to reduce the model and verified model fit by inspecting model residuals for normality and homoscedasticity. All statistical analyses were conducted in R 4.0.0 (R Core Team, 2020).

\section{RESULTS}

\section{Gut Passage Times}

During three complete elephant follows, we encountered 437 elephant dungs, 118 of which contained experimental seeds, and recovered 845 experimental seeds ( 842 pellets and 3 tin seeds). No seeds were found after 4.7 days, suggesting that following

\footnotetext{
${ }^{1}$ https://developers.google.com/earth-engine/datasets/catalog/COPERNICUS_ Landcover_100m_Proba-V-C3_Global
} 


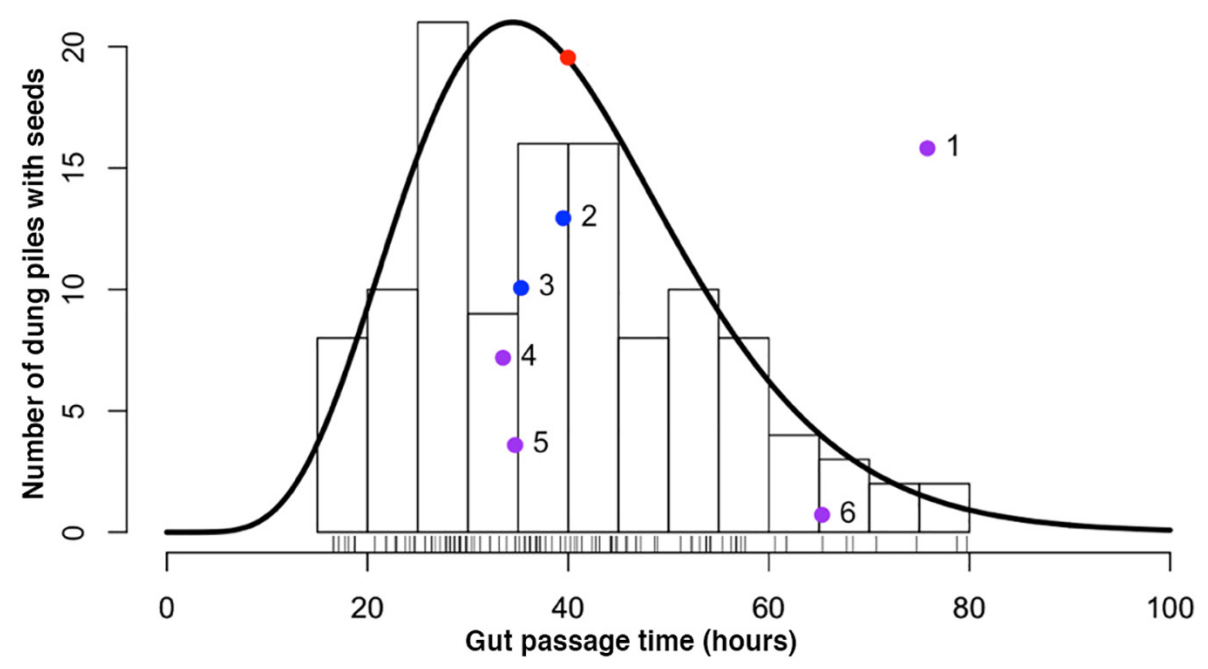

FIGURE 2 | Distribution of gut passage times from baiting trials on wild forest elephants in Gabon. The histogram shows the number of dung piles containing experimental seeds over time. The red point depicts the mean GPT from these observed data $39.5 \mathrm{~h}$ (sd = $14.5 \mathrm{~h}$ ). The curve over the histogram is the best fitting gamma distribution $[\Gamma(k=7.6, \Theta=5.2)$ ], with a mean GPT of 39.5 h. Numbered points represent GPT estimates from studies of $L$. africana (purple) and E. maximus (blue) with the height of each point representing the number of dung piles with seeds from which the estimates were derived. The numbers by the points correspond to: (1) captive L. africana using iButtons ( $n=3,2$ females, and 1 male) (Beirne et al., 2019); (2) captive E. maximus using beads ( $n=4$, 1 male, and 3 females) (Campos-Arceiz et al., 2008); (3) captive E. maximus using seeds of Dillenia indica ( $n=6$, all females) (Harich et al., 2016); (4) captive L. africana using melon seeds ( $n=4,2$ males, and 2 females) (Bunney et al., 2017); (5) captive $L$. africana using mango seeds ( $n=4,2$ males, and 2 females) (Bunney et al., 2017); and (6) captive $L$. africana using iButtons ( $n=4,1$ male, and 3 females) (Kinahan et al., 2007).

elephants for 10 days was sufficient to recover most seeds. Of dung with recovered seeds, $47 \%$ of dung piles were attributed to the adult female, $21 \%$ to juveniles, and $32 \%$ of dung piles could not be reliably categorized as adult or juvenile dung. Mean GPT was $42.2 \mathrm{~h}$ [95\% CI: 37.0, 47.4] for females, $34.8 \mathrm{~h}$ [28.2, 41.5] for juveniles, and $41.1 \mathrm{~h}[37.0,45.2]$ for undefined dung piles. Because the dung pile categories did not differ significantly in GPT $\left(F_{2,106}=1.30, p=0.278\right)$, we combined all dung to estimate mean GPT and its distribution.

From the field data, we estimated a mean GPT of $39.8 \mathrm{~h}$, and a range of $16.6-113.7 \mathrm{~h}$ (Beirne et al., 2019). The mean GPT of tin seeds was $65.6 \mathrm{~h}$ (range 29.2-113.7 h). We fit the 118 observations of GPTs with a gamma distribution with shape parameter $(k=7.6)$ and scale parameter $(\Theta=5.2)$. The mean GPT from the gamma distribution was $39.5 \mathrm{~h}$ (95\% CI: 16.6, 72.2) (Figure 2). Our estimates of mean GPT are similar to estimates from previous studies of captive Asian (Elephas maximus) and savanna (Loxodonta africana) elephants that include both male and female adult individuals (Figure 2).

\section{Seed Dispersal Distances}

The median seed dispersal distance of all elephants combined was $5.3 \mathrm{~km}($ mean $=6.5 \mathrm{~km}, 95 \%$ quantile $=16.4 \mathrm{~km})($ Figures 3, 4). Forest elephants dispersed $89 \%$ of seeds farther than $1 \mathrm{~km}$ and $10 \%$ of seeds farther than $14.1 \mathrm{~km}$. Evaluating dispersal across all 96 individual elephants, the median dispersal across all individual medians was $4.4 \mathrm{~km}$ and ranged from 2.3 to $6.0 \mathrm{~km}$; average mean dispersal distance was $5.3 \mathrm{~km}$ and ranged from 2.7 to $7.1 \mathrm{~km}$.

To investigate long distance dispersal by forest elephants, we estimated maximum dispersal distances. Using the mean GPT of
$39.5 \mathrm{~h}$ from the gamma distribution (gamma distribution ranges from 0 to infinity, thus a maximum GPT cannot be defined) and the longest observed movements, we determined maximum seed dispersal distances of $101 \mathrm{~km}$ for a female and $87.4 \mathrm{~km}$ for a male elephant. Mean maximum dispersal for all 96 elephants was 40.1 km (95\% CI: 20.0, 70.8).

Correlation between longitude and latitude of dispersal locations can assess the degree of asymmetry in dispersal. For several elephants, dispersal was strongly directional (max $r=0.701$, min $r=0.91$; Figure 5), but across all elephants the correlation was near 0 (mean $r=-0.09$; mean $\mathrm{x}=0.001$, mean $y=0.005$ ), indicating that on average seed dispersal was symmetrical in distribution (e.g., Figure 4).

\section{Drivers of Variation in Seed Dispersal Distance}

Neither human disturbance (HFI), habitat openness, nor interaction between sex and site significantly influenced median seed dispersal distances. Therefore, the final model included significant effects of exploratory behavior, sex, and site $\left(F_{8,87}=5.37, R^{2}=0.269\right.$, and $\left.p<0.001\right)$. The measure of exploratory behavior ranged from -1.1 (idler) to 1.3 (explorer) with a median of 0 . For every one-unit change in exploratory behavior, median seed dispersal increased by $0.45 \mathrm{~km}(t=2.41$, $p=0.018)$. Male elephants dispersed seeds $0.81 \mathrm{~km}$ farther than female elephants $(t=3.98, p<0.001)$. Elephants at Mwagne $(t=2.98, p=0.004)$, Moukalaba Doudou $(t=2.09, p=0.040)$, and Wonga Wongué $(t=2.77, p=0.007)$ dispersed seeds $1.0 \mathrm{~km}, 0.70 \mathrm{~km}$, and $0.80 \mathrm{~km}$ farther than elephants at Ivindo (the base contrast). 


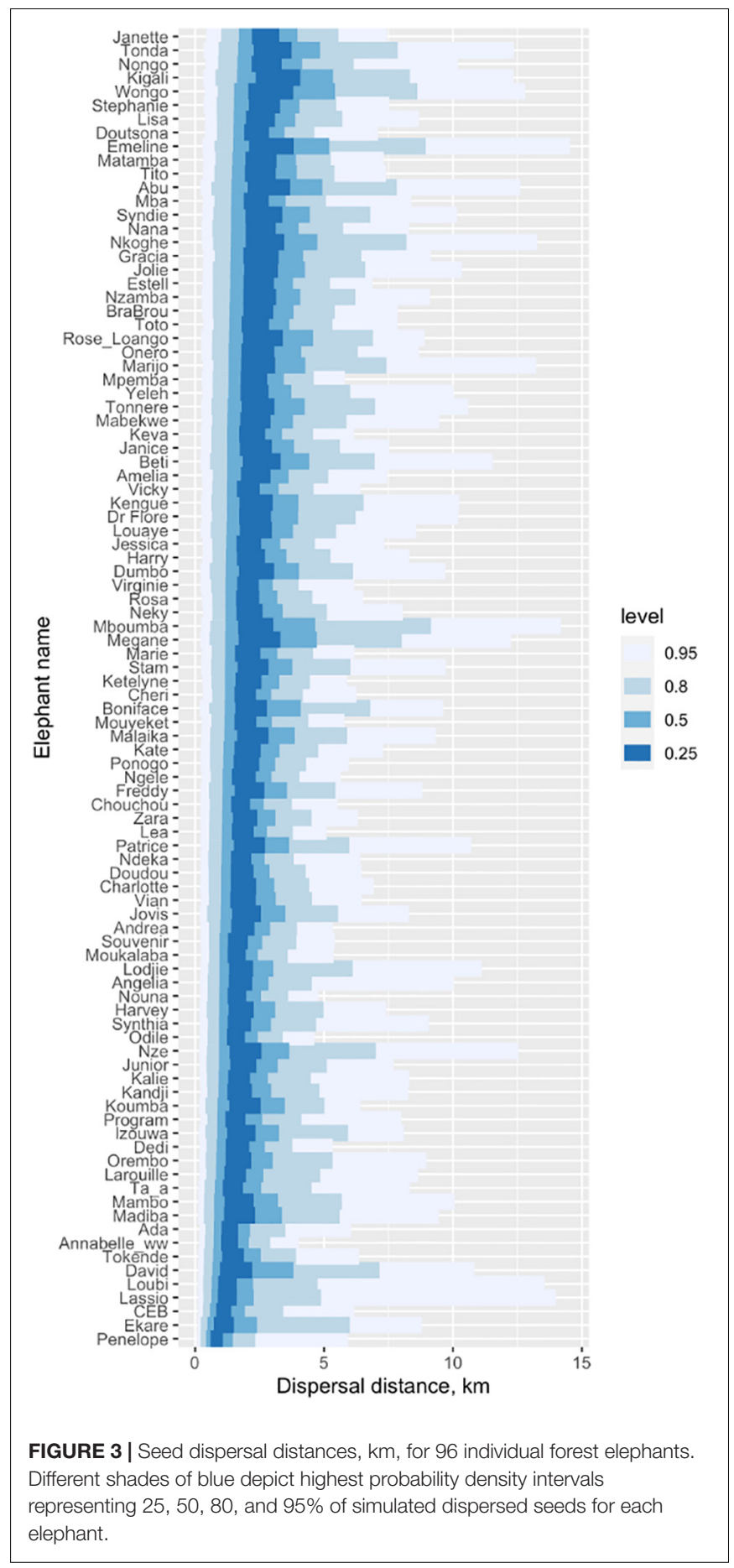

To further assess the potential drivers of differences in seed dispersal distances among sites, we examined the proportional use of closed habitat by elephants. With approximately $99 \%$ of GPS fixes being in forest in Ivindo, Minkébé, and Mwagna NPs, compared to $81.2 \%$ in Moukoulaba Doudou, $62.6 \%$ in Loango, and $58.0 \%$ in Wonga Wongué, proportional use of forest differed significantly among sites, but not between sexes (beta regression, pseudo $R^{2}=67.6 \%$ ). The finding that males

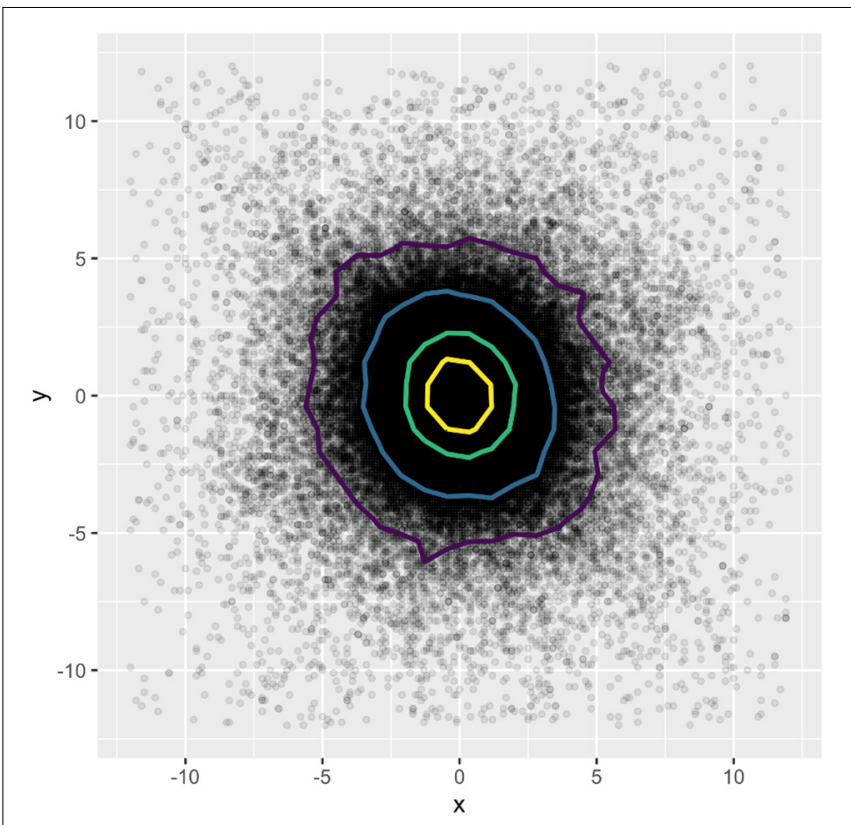

FIGURE 4 | Simulated seed shadow generated by forest elephants integrating GPT data and movement data from 96 elephants. $x$ and y represent distances east-west and north-south in $\mathrm{km}$. Colored lines show the location of 25, 50, 75 , and $90 \%$ of dispersed seeds.

and females did not differ in their proportional use of forest lends support to our above result that differences in dispersal distances among sites are not due to the uneven sex ratios of collared elephants. However, the fact that seed dispersal distances did not vary by habitat given the large differences in use of forest among sites was surprising but indicates that other environmental differences among sites must be identified and measured.

\section{DISCUSSION}

By integrating gut passage data from wild forest elephants with movement patterns from 96 GPS-collared individuals, we support previous findings that forest elephants are important long-distance seed dispersers (Blake et al., 2009). Median seed dispersal distance was $5.3 \mathrm{~km}$, with $89 \%$ of seeds dispersed farther than $1-\mathrm{km}$ and $10 \%$ of seeds dispersed farther than 14-km. At average GPT, maximum simulated seed dispersal was $101 \mathrm{~km}$ and average maximum dispersal of all elephants was $40.1 \mathrm{~km}$. These dispersal distances are well beyond the local neighborhood of parent trees, and likely contribute to gene flow between populations and colonization of new habitats. Seed dispersal distances, however, depend on both extrinsic and intrinsic variables. Median seed dispersal distances varied significantly across sites and with both the sex and exploratory behavior of elephants. Our study highlights the importance of intraspecific variation among seed dispersers; through the portfolio effect intraspecific variation in dispersal can increase the range of habitats 

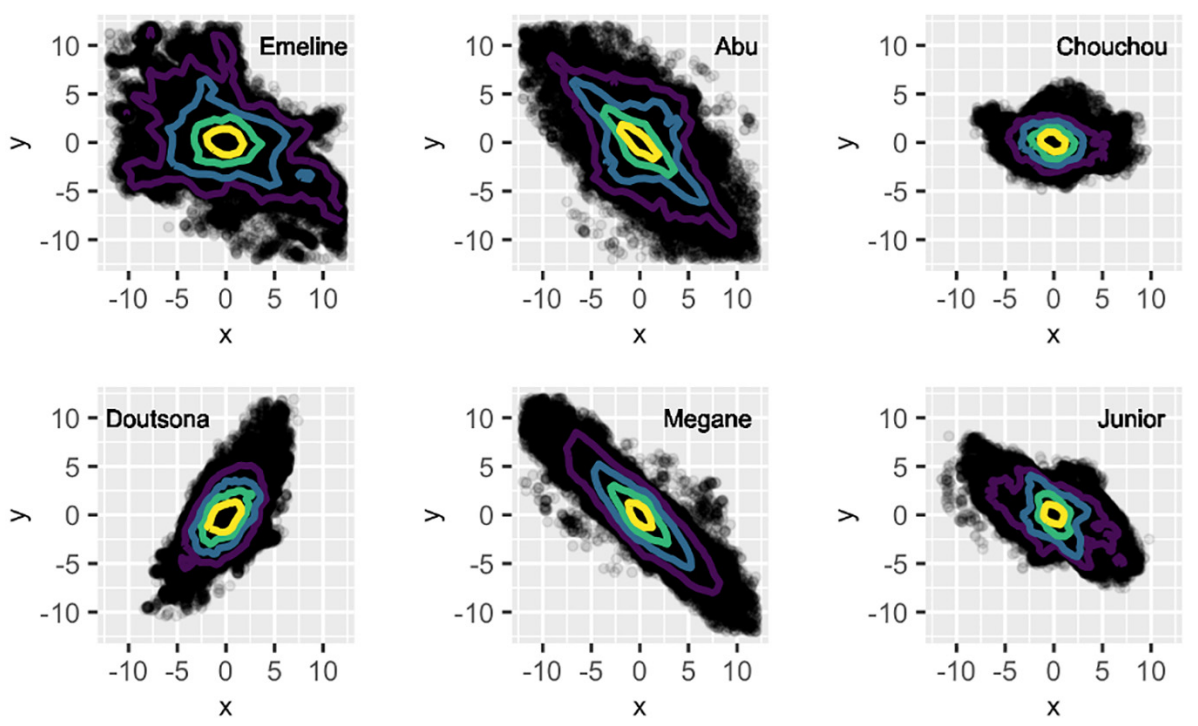

FIGURE 5 | Simulated seed shadows generated by individual forest elephants integrating GPT data and movement data. $\mathrm{x}$ and y represent distances east-west and north-south in $\mathrm{km}$. Colored lines show the location of 25, 50, 75, and 90\% of dispersed seeds. These individual elephants were selected to illustrate seed dispersal patterns that deviate from the overall symmetrical distribution (i.e., Figure 4): Emeline $(r=-0.56)$, Abu $(r=-0.71)$, Chouchou $(r=-0.14)$, Doutsona ( $r=0.58)$,

Megane $(r=-0.91)$, and Junior $(r=-0.56)$.

and conditions where seeds are dispersed, improving the likelihood of population persistence under unfavorable events (Bolnick et al., 2011).

Among tropical animals, forest elephants play a keystone role as seed dispersers because of the high number of fruit species they consume, their slow GPTs, and relatively long dispersal distances (Blake et al., 2009; Beirne et al., 2020). Large, frugivorous birds like hornbills can fly nearly 300 miles (Holbrook et al., 2002), but their faster GPTs limit maximum seed dispersal distance to 7-km (Holbrook and Smith, 2000). Compared to other elephant species, forest elephants demonstrate longer median and maximum dispersal distances. Savanna elephants (Loxodonta africana) move $50 \%$ of ingested seeds over $2.5 \mathrm{~km}$ from the parent plant, with a maximum dispersal distance of $65 \mathrm{~km}$ (Bunney et al., 2017). Asian elephants (Elephas maximus) disperse $50 \%$ of seeds $>1.2 \mathrm{~km}$, with a maximum distance of $5.8 \mathrm{~km}$ (Campos-Arceiz et al., 2008).

The distances elephants disperse seeds vary across sites. Elephants in Wonga Wongué dispersed seeds 1-km farther on average than elephants in Ivindo. Surprisingly, even though forest elephants move faster through grasslands than other habitats (Mills et al., 2018) and two (Wonga Wongué and Moukoulaba Doudou) of the three sites with significantly longer seed dispersal than Ivindo contain extensive grasslands, seed dispersal distances were not associated with the greater presence and proportional use of open habitat by elephants. But site-level variation in dispersal distances could be caused by a multitude of factors influencing movement, including differences in landscape heterogeneity (Levey et al., 2008) and configuration (Uriarte et al., 2011), presence of clearings (baïs), topography, weather, and spatial patterns in food resources. For example, rainfall, and to a lesser extent fruit availability, predict the proportion of time forest elephants spend in long, directionally persistent movements (Beirne et al., 2020). Thus, site-specific environmental characteristics can significantly influence frugivore movement patterns, and consequently, dispersal patterns, potentially driving among population differences in plant distribution and abundance (Nuñez et al., 2019).

Despite strong effects of poaching and human activities on elephant populations and movement (Beirne et al., 2021), seed dispersal distances did not vary significantly with human disturbance. Like Markl et al. (2012), we found that dispersal distances were slightly, but not significantly, lower in disturbed areas. Failure to detect an effect might be due to our use of HFI - a relatively coarse metric of human disturbance - and because most of the focal elephants inhabited protected areas where human pressure should be weak. Our study also focused only on dispersal distance, whereas hunting and logging could affect seed dispersal by altering rates of tree visitation and fruit removal (Markl et al., 2012). Alternatively, rather than reducing movement, forest elephants might respond to human activities in other ways, such as moving nocturnally, that could have weaker effects on seed dispersal.

Seed dispersal distances of individual forest elephants vary with sex and behavior. Males tended to disperse seeds farther, consistent with their larger home ranges and lower site fidelity (Beirne et al., 2021). Sex-based effects are likely even stronger than our findings because males are large, have higher energy needs, and therefore likely consume more fruit and disperse more seeds than females. In addition, mammalian GPT tends to scale with mass (Abraham et al., 2021); thus, male GPTs should be slower than female GPTs. 
Behavioral syndromes, specifically the degree to which elephants are idlers or explorers, significantly affect seed dispersal distances. The most exploratory elephants dispersed seeds $1.1 \mathrm{~km}$ farther than the least exploratory elephants and $0.6 \mathrm{~km}$ farther than elephants with balanced movement behavior. This is consistent with findings that colonization, invasion, and range expansion are often associated with bolder, more aggressive, or more exploratory animals (Duckworth and Badyaev, 2007; Chapple et al., 2012). Within-population variation in behavioral types of elephants can result in seeds being deposited in a more diverse array of places, including a greater range of distances away from parent plants. This will result in dispersal kernels with fatter tails. The same behavioral traits, like boldness and exploration, that positively correlate with dispersal distances might differentially affect other stages of seed dispersal. For example, fast explorers might be more likely to first find fruits that are larger, brighter or more abundant (Zwolak and Sih, 2020); alternatively, explorers can be poor dispersers if they collect fewer seeds before moving on (weaker area-concentrated search: Spiegel et al., 2017).

Our estimates of LDD for forest elephants are likely conservative for several reasons. First, our GPT estimates are largely derived from small pellets and large seeds likely have longer GPTs. In fact, the three large tin seeds recovered from our baiting trials had an average GPT of $65.6 \mathrm{~h}$. Second, we based our estimates of maximum seed dispersal on median GPT, meaning that half of seeds would be passed more slowly and dispersed farther. Third, our GPT estimates were based on data from a single female elephant and two juveniles, which may not be fully reflective of larger, male elephants. Reassuringly, however, mean GPT from other studies and elephant species correspond closely to our estimate of mean GPT (Figure 2). This suggests that estimating GPT from captive elephants is an effective (and less laborious) alternative to following wild elephants in the field. Using captive elephants has the advantage of being able to control for elephant characteristics (e.g., sex, age, size, and species) and to manipulate diet items (e.g., seed size, fruit type), enabling the identification of potentially important factors that drive GPT and dispersal distances. For example, if large seeds are retained in the gut longer than small seeds (Kleyheeg et al., 2018), then elephants might provide two types of dispersal services.

Our study demonstrates the importance of forest elephants in LDD and the strong effects of extrinsic (site) and intrinsic (sex and behavioral type) variables on seed dispersal distances. It also reveals gaps in our knowledge of seed dispersal by large, frugivorous animals. The specific environmental characteristics of sites that influence disperser movements need to be investigated, particularly in the face of global climate change, habitat fragmentation, and diminishing intact wilderness. In addition, life history strategies and stages of individuals, such as phenotypic, size-, and age-related variation influence animal GPTs and movements (Byrne et al., 2019; Abraham et al., 2021). While we identified individual variation in elephant movement, individual variation in fruit consumption rates and seed deposition patterns could also strongly influence the patterns and outcomes of seed dispersal (Markl et al., 2012).

In a rapidly changing world, failure of plant species to reproduce could alter the species composition of tropical forests and reduce fruit resources to the detriment of fruit-dependent animals like forest elephants (Bush et al., 2020). Conservation of seed dispersal processes depends on protection of keystone disperser species. Thus, we need to know which habitats to conserve and possibly which individuals to protect. Male elephants, for example, are often targeted by poachers for their large tusks (Mondol et al., 2014); but bolder, more exploratory males may be more likely to disperse plant species into new or regenerating habitats. Understanding extrinsic and intrinsic drivers of seed dispersal can improve management of species critical to broader ecosystem and biosphere functioning.

\section{DATA AVAILABILITY STATEMENT}

The original contributions presented in the study are included in the article/supplementary material, further inquiries can be directed to the corresponding author.

\section{ETHICS STATEMENT}

The animal study was reviewed and approved by Duke Institutional Animal Care and Use Committee, Duke University.

\section{AUTHOR CONTRIBUTIONS}

JP conceived the ideas and led the writing of the manuscript. $\mathrm{CB}$, MB, SK, JK, WM, GO, JM, and TN collected the data. CR, JP, CB, TM, CN, LJ, and SX analyzed the data. All authors contributed critically to the drafts and gave final approval for publication and designed the methodology.

\section{FUNDING}

The elephant collaring program was funded by a cooperative agreement from the United States Fish and Wildlife Service to ANPN. The Duke Bass Connections program generously funded the GPT research.

\section{ACKNOWLEDGMENTS}

We thank the Gabonese Government, particularly the Agence Nationale des Parcs Nationaux (ANPN) for logistical support, permission to work in Ivindo National Park, and permission to use the elephant movement data. We also thank the Centre National de la Recherche Scientifique (CENAREST) for permission to conduct the research and Université Omar Bongo for its collaboration. 


\section{REFERENCES}

Abraham, A. J., Prys-Jones, T. O., De Cuyper, A., Ridenour, C., Hempson, G. P., Hocking, T., et al. (2021). Improved estimation of gut passage time considerably affects trait-based dispersal models. Funct. Ecol. 35, 860-869. doi: 10.1111/13652435.13726

Beaune, D., Fruth, B., Bollache, L., Hohmann, G., and Bretagnolle, F. (2013). Doom of the elephant-dependent trees in a Congo tropical forest. For. Ecol. Manage. 295, 109-117. doi: 10.1016/j.foreco.2012.12.041

Beirne, C., Houslay, T. M., Morkel, P., Clark, C. J., Fay, M., Okouyi, J., et al. (2021). African forest elephant movements depend on time scale and individual behavior. Sci. Rep. 11:12634. doi: 10.1038/s41598-021-91627-z

Beirne, C., Meier, A. C., Brumagin, G., Jasperse-Sjolander, L., Lewis, M., Masseloux, J., et al. (2020). Climatic and resource determinants of forest elephant movements. Front. Ecol. Evol. 8:96. doi: 10.3389/fevo.2020.00096

Beirne, C., Nuñez, C. L., Baldino, M., Kim, S., Knorr, J., Minich, T., et al. (2019). Estimation of gut passage time of wild, free roaming forest elephants. Wildlife Biol. 2019, 1-7. doi: 10.2981/wlb.00543

Blake, S., Deem, S. L., Mossimbo, E., Maisels, F., and Walsh, P. (2009). Forest elephants: Tree planters of the Congo. Biotropica 41, 459-468. doi: 10.1111/j. 1744-7429.2009.00512.x

Bolnick, D. I., Amarasekare, P., Araújo, M. S., Bürger, R., Levine, J. M., Novak, M., et al. (2011). Why intraspecific trait variation matters in community ecology. Trends Ecol. Evol. 26, 183-192. doi: 10.1016/j.tree.2011.01.009

Bunney, K., Bond, W. J., and Henley, M. (2017). Seed dispersal kernel of the largest surviving megaherbivore-the African savanna elephant. Biotropica 49, 395-401. doi: 10.1111/btp.12423

Bush, E. R., Whytock, R. C., Bahaa-el-din, L., Bourgeois, S., Bunnefeld, N., Cardoso, A. W., et al. (2020). Long-term collapse in fruit availability threatens Central African forest megafauna. Science 7791:eabc7791. doi: 10.1126/science.abc 7791

Byrne, A. W., O’Keefe, J., Buesching, C. D., and Newman, C. (2019). Push and pull factors driving movement in a social mammal: context dependent behavioral plasticity at the landscape scale. Curr. Zool. 65, 517-525. doi: 10.1093/cz/zoy081

Cain, M. L., Milligan, B. G., and Strand, A. E. (2000). Long-distance seed dispersal in plant populations. Am. J. Bot. 87, 1217-1227. doi: 10.2307/2656714

Campos-Arceiz, A., and Blake, S. (2011). Megagardeners of the forest - the role of elephants in seed dispersal. Acta Oecol. 37, 542-553. doi: 10.1016/j.actao.2011. 01.014

Campos-Arceiz, A., Larrinaga, A. R., Weerasinghe, U. R., Takatsuki, S., Pastorini, J., Leimgruber, P., et al. (2008). Behavior rather than diet mediates seasonal differences in seed dispersal by Asian elephants. Ecology 89, 2684-2691. doi: 10.1890/07-1573.1

Chapple, D. G., Simmonds, S. M., and Wong, B. B. M. (2012). Can behavioral and personality traits influence the success of unintentional species introductions? Trends Ecol. Evol. 27, 57-64. doi: 10.1016/j.tree.2011.09.010

Davidson, A. D., Hamilton, M. J., Boyer, A. G., Brown, J. H., and Ceballos, G. (2009). Multiple ecological pathways to extinction in mammals. Proc. Natl. Acad. Sci. U.S.A. 106, 10702-10705. doi: 10.1073/pnas.0901956106

Duckworth, R. A., and Badyaev, A. V. (2007). Coupling of dispersal and aggression facilitates the rapid range expansion of a passerine bird. Proc. Natl. Acad. Sci. U.S.A. 104, 15017-15022. doi: 10.1073/pnas.0706174104

Guimarães, P. R., Galetti, M., and Jordano, P. (2008). Seed dispersal anachronisms: rethinking the fruits extinct megafauna ate. PLoS One 3:1745. doi: 10.1371/ journal.pone. 0001745

Harich, F. K., Treydte, A. C., Ogutu, J. O., Roberts, J. E., Savini, C., Bauer, J. M., et al. (2016). Seed dispersal potential of Asian elephants. Acta Oecol. Int. J. Ecol. 77, 144-151. doi: 10.1016/j.actao.2016.10.005

Harrison, R. D., Tan, S., Plotkin, J. B., Slik, F., Detto, M., Brenes, T., et al. (2013). Consequences of defaunation for a tropical tree community. Ecol. Lett. 16, 687-694. doi: 10.1111/ele.12102

Holbrook, K. M., and Smith, T. B. (2000). Seed dispersal and movement patterns in two species of ceratogymna hornbills in a west african tropical lowland forest. Oecologia 125, 249-257. doi: 10.1007/s004420000445

Holbrook, K. M., Smith, T. B., and Hardesty, B. D. (2002). Implications of longdistance movements of frugivorous rain forest hornbills. Ecography (Cop.) 25, 745-749. doi: 10.1034/j.1600-0587.2002.250610.x
Huijbregts, B., De Wachter, P., Ndong Obiang, L. S., and Akou, M. E. (2003). Ebola and the decline of gorilla Gorilla gorilla and chimpanzee Pan troglodytes populations in Minkebe Forest, north-eastern Gabon. ORYX 37, 437-443. doi: 10.1017/S0030605303000802

Janzen, D. H. (1970). Herbivores and the number of tree species in tropical forests. Am. Nat. 104, 501-528.

Kays, R., Crofoot, M. C., Jetz, W., and Wikelski, M. (2015). Terrestrial animal tracking as an eye on life and planet. Science 348:aaa2478. doi: 10.1126/science. aaa2478

Kinahan, A. A., Inge-moller, R., Bateman, P. W., Kotze, A., and Scantlebury, M. (2007). Body temperature daily rhythm adaptations in African savanna elephants (Loxodonta africana). Physiol. Behav. 92, 560-565. doi: 10.1016/j. physbeh.2007.05.001

Kleyheeg, E., Nolet, B. A., Otero-Ojea, S., and Soons, M. B. (2018). A mechanistic assessment of the relationship between gut morphology and endozoochorous seed dispersal by waterfowl. Ecol. Evol. 8, 10857-10867. doi: 10.1002/ece3.4544

Levey, D. J., Tewksbury, J. J., and Bolker, B. M. (2008). Modelling long-distance seed dispersal in heterogeneous landscapes. J. Ecol. 96, 599-608. doi: 10.1111/j. 1365-2745.2008.01401.x

Levin, S. A., Muller-Landau, H. C., Nathan, R., and Chave, J. (2003). The ecology and evolution of seed dispersal: a theoretical perspective. Annu. Rev. Ecol. Evol. Syst. 34, 575-604. doi: 10.1146/annurev.ecolsys.34.011802.132428

Maisels, F., Strindberg, S., Blake, S., Wittemyer, G., Hart, J., Williamson, E. A., et al. (2013). Devastating decline of forest elephants in central Africa. PLoS One 8:56469. doi: 10.1371/journal.pone.0059469

Markl, J. S., Schleuning, M., Forget, P. M., Jordano, P., Lambert, J. E., Traveset, A., et al. (2012). Meta-analysis of the effects of human disturbance on seed dispersal by animals. Conserv. Biol. 26, 1072-1081. doi: 10.1111/j.1523-1739.2012.01 927.x

Martínez-Íñigo, L., Baas, P., Klein, H., Pika, S., and Deschner, T. (2021). Home range size in central chimpanzees (Pan troglodytes troglodytes) from Loango National Park. Gabon. Primates 62, 723-734. doi: 10.1007/s10329-021-00927-5

Mills, E. C. M., Poulsen, J. R., Fay, J. M., Morkel, P., Clark, C. J., Meier, A. M., et al. (2018). Forest elephant movement and habitat use in a tropical forest-grassland mosaic in Gabon. PLoS One 13:199387. doi: 10.1371/journal.pone.0199387

Mondol, S., Mailand, C. R., and Wasser, S. K. (2014). Male biased sex ratio of poached elephants is negatively related to poaching intensity over time. Conserv. Genet. 15, 1259-1263. doi: 10.1007/s10592-014-0603-2

Nathan, R. (2006). Long-distance dispersal of plants. Science 313, 786-788. doi: 10.1126/science. 1124975

Nuñez, C. L., Clark, J. S., Clark, C. J., and Poulsen, J. R. (2019). Low-intensity logging and hunting have long-term effects on seed dispersal but not fecundity in Afrotropical forests. AoB Plants 11, 1-17. doi: 10.1093/aobpla/ply074

Poulsen, J. R., Koerner, S. E., Moore, S., Medjibe, V. P., Blake, S., Clark, C. J., et al. (2017). Poaching empties critical Central African wilderness of forest elephants. Curr. Biol. 27, R134-R135. doi: 10.1016/j.cub.2017.01.023

Poulsen, J. R., Medjibe, V. P., White, L. J. T., Miao, Z., Banak-Ngok, L., Beirne, C., et al. (2020). Old growth Afrotropical forests critical for maintaining forest carbon. Glob. Ecol. Biogeogr. 29, 1785-1798. doi: 10.1111/geb.13150

Poulsen, J. R., Rosin, C., Meier, A., Mills, E., Nuñez, C. L., Koerner, S. E., et al. (2018). The ecological consequences of forest elephant declines for Afrotropical forests. Conserv. Biol. 32, 559-567. doi: 10.1111/cobi.13035

R Core Team (2020). R: A Language and Environment for Statistical Computing. Vienna: R Core Team.

Russo, S. E., Portnoy, S., and Augspurger, C. K. (2006). Incorporating animal behavior into seed dispersal models: Implications for seed shadows. Ecology 87, 3160-3174.

Sannier, C., McRoberts, R. E., Fichet, L. V., and Makaga, E. M. K. (2014). Using the regression estimator with landsat data to estimate proportion forest cover and net proportion deforestation in gabon. Remote Sens. Environ. 151, 138-148. doi: 10.1016/j.rse.2013.09.015

Sih, A., Bell, A., and Johnson, J. C. (2004). Behavioral syndromes: An ecological and evolutionary overview. Trends Ecol. Evol. 19, 372-378. doi: 10.1016/j.tree. 2004.04.009

Sih, A., Cote, J., Evans, M., Fogarty, S., and Pruitt, J. (2012). Ecological implications of behavioural syndromes. Ecol. Lett. 15, 278-289. doi: 10.1111/j.1461-0248. 2011.01731.x 
Spiegel, O., Leu, S. T., Bull, C. M., and Sih, A. (2017). What's your move? Movement as a link between personality and spatial dynamics in animal populations. Ecol. Lett. 20, 3-18. doi: 10.1111/ele.12708

Terada, S., Mikolo Yobo, C., Moussavou, G.-M., and Matsuura, N. (2021). Human-elephant conflict around moukalaba-doudou national park in gabon: socioeconomic changes and effects of conservation projects on local tolerance. Trop. Conserv. Sci. 14:1. doi: 10.1177/19400829211026775

Uriarte, M., Anciaes, M., Da Silva, M. T. B., Rubim, P., Johnson, E., and Bruna, E. M. (2011). Disentangling the drivers of reduced long-distance seed dispersal by birds in an experimentally fragmented landscape. Ecology 92, 924-937. doi: 10.1890/10-0709.1

Vidal, M. M., Pires, M. M., and Guimarães, P. R. (2013). Large vertebrates as the missing components of seed-dispersal networks. Biol. Conserv. 163, 42-48. doi: 10.1016/j.biocon.2013.03.025

Wandrag, E. M., Dunham, A. E., Duncan, R. P., and Rogers, H. S. (2017). Seed dispersal increases local species richness and reduces spatial turnover of tropical tree seedlings. Proc. Natl. Acad. Sci. U.S.A. 114, 10689-10694. doi: 10.1073/pnas. 1709584114

Wildlife Conservation Society - WCS, and Center for International Earth Science Information Network - CIESIN - Columbia University (2005). Last of the Wild Project, Version 2, 2005 (LWP-2): Global Human Footprint Dataset (Geographic). Palisades, NY: NASA Socioeconomic Data and Applications Center (SEDAC). doi: 10.7927/H4M61H5F
Zwolak, R., and Sih, A. (2020). Animal personalities and seed dispersal: a conceptual review. Funct. Ecol. 34, 1294-1310. doi: 10.1111/1365-2435. 13583

Conflict of Interest: The authors declare that the research was conducted in the absence of any commercial or financial relationships that could be construed as a potential conflict of interest.

Publisher's Note: All claims expressed in this article are solely those of the authors and do not necessarily represent those of their affiliated organizations, or those of the publisher, the editors and the reviewers. Any product that may be evaluated in this article, or claim that may be made by its manufacturer, is not guaranteed or endorsed by the publisher.

Copyright (c) 2021 Poulsen, Beirne, Rundel, Baldino, Kim, Knorr, Minich, Jin, Núñez, Xiao, Mbamy, Obiang, Masseloux, Nkoghe, Ebanega, Clark, Fay, Morkel, Okouyi, White and Wright. This is an open-access article distributed under the terms of the Creative Commons Attribution License (CC BY). The use, distribution or reproduction in other forums is permitted, provided the original author(s) and the copyright owner(s) are credited and that the original publication in this journal is cited, in accordance with accepted academic practice. No use, distribution or reproduction is permitted which does not comply with these terms. 